\title{
Auricular unipolar electrocardiography in the prevention of bundle lesions during repair of septal defects
}

\author{
J. W IE BE R D I N K ${ }^{1}$ A N D F. L. ME I J LER \\ From the Departments of Surgery and Cardiology, University of Amsterdam
}

Electrocardiography is the best way to detect and classify conduction disturbances. In spite of this, it has gained little appreciation as an aid in the prevention of bundle lesions during open repair of interatrial or interventricular septal defects, since it is generally held that warnings from the cardiologist do not reach the surgeon until irreversible damage to the conduction system has been done. We feel that electrocardiography has been disappointing because the use of conventional limb leads makes the recognition of $P$ waves difficult during the phase of open repair. Opening of the thorax causes a decrease of peripheral E.C.G. voltage. At the same time interpretation of the conventional E.C.G. record is impeded by alternating current and other artefacts often present in an operating theatre. In this paper a simple

1 Present address: Department of Cardiovascular Surgery, University of Utrecht method is presented which makes electrocardiography more effective in the prevention of surgically induced bundle lesions.

The value of other methods of preventing these lesions is not discussed here.

\section{METHODS}

A ring-shaped ( $\phi 2 \mathrm{~mm}$.) platinum wire electrode is sutured to the right auricular surface with an atraumatic nylon stitch before the heart is opened. The electrode is connected to the $\mathrm{V}$ lead of an ordinary electrocardiograph. The amplification of the apparatus is adjusted in such a way that $\mathbf{P}$ waves of suitable size are recorded. At the beginning an elevation of the P-Ta segment can often be seen due to the injury caused by the suture. The $\mathbf{P}$ waves recorded in this way show a distinct intrinsic deflexion facilitating their recognition from the QRS complex (Fig. 1).
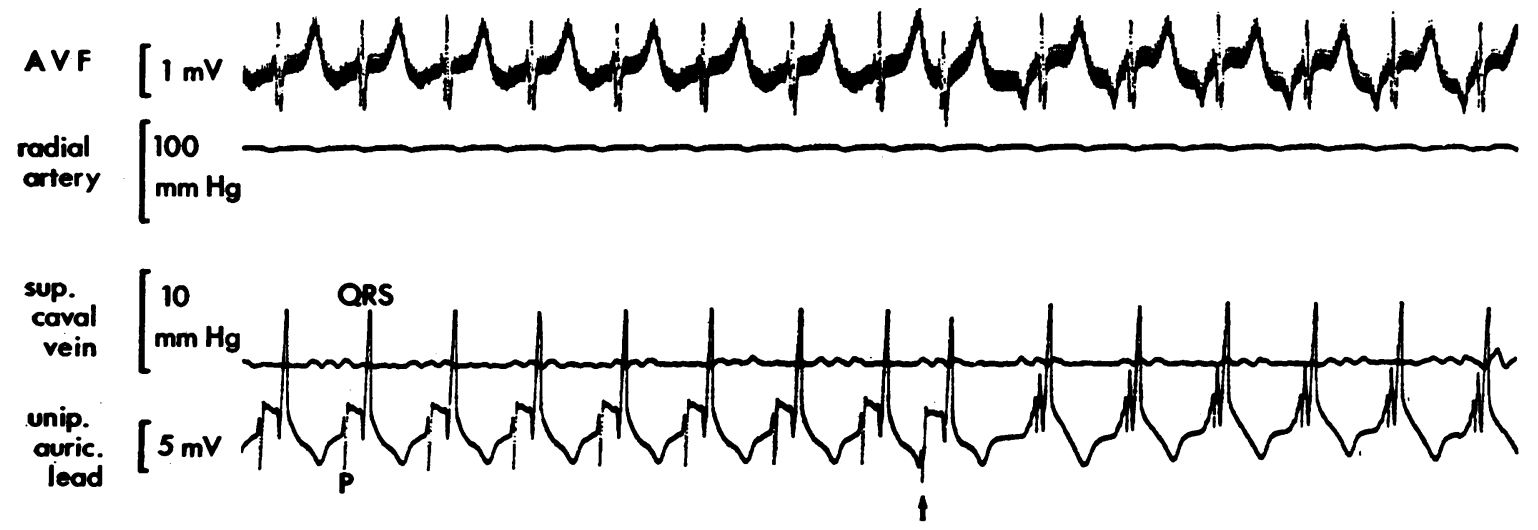

FIG. 1. Unipolar auricular electrocardiogram made during open repair of an interatrial septal defect. The record shows conventional AVF lead (top line), intra-arterial pressure (second line: radial artery), the pressure in the superior vena cava (third line: superior caval vein), and unipolar auricular lead (bottom line). The distinct intrinsic deflexion in the $P$ wave can be seen together with the elevation of the P-Ta segment. After the auricular premature beat (arrow) the sinus rhythm changes into a nodal rhythm. 
Figure 1 is a representative record made during open repair of a primum-defect of the interatrial septum complicated by a cleft mitral valve in a 15-year-old girl.

Operation was performed on the girl in March 1960 using normothermic heart-lung bypass. When the suturing of the Teflon patch approached the narrow rim between the mitral and tricuspid valves, the atrial surface lead showed several definite prolongations of the P-R intervals, while the $P$ waves in the limb leads were hardly recognizable. Guided by the unipolar auricular lead the sutures were placed in such a way that conduction disturbances were avoided and satisfactory closure of the defect was achieved.
Unipolar auricular electrocardiography can help to prevent heart block during open repair of septal defects. For this purpose conventional limb leads are unsatisfactory because they do not facilitate the early recognition of $P-R$ interval changes under conditions of open heart surgery. The use of an atrial surface electrode overcomes this difficulty and renders electrocardiographical guidance of the surgeon possible.

Our thanks are due to Professor D. Durrer for his encouragement and advice.

\section{REFERENCE}

van der Kooi, M. W., Durrer, D., van Dam, R. Th., and van der Tweel, L. H. (1956). Amer. Heart J., 51, 684. 